\title{
Five-Year Outcomes and Cardiac Remodeling Following Left Atrial Appendage Occlusion
}

\author{
Baoxin Liu',* \\ Jiachen Luo',* \\ Mengmeng Gong' \\ Zhiqiang $\mathrm{Li}^{\prime}$ \\ Beibei Shi ${ }^{1}$ \\ Xingxu Zhang' \\ Xinqiang $\mathrm{Han}^{2}$ \\ Yidong Wei ${ }^{1}$ \\ 'Department of Cardiology, Shanghai \\ Tenth People's Hospital, Tongji University \\ School of Medicine, Shanghai, People's \\ Republic of China; ${ }^{2}$ Electrophysiology and \\ Arrhythmia Services, Reid Health, Indiana \\ University School of Medicine, Richmond, \\ IN, 47374, USA
}

*These authors contributed equally to this work
Correspondence: Yidong Wei

Department of Cardiology, Shanghai

Tenth People's Hospital, Tongji University

School of Medicine, 30I Middle Yanchang

Road, Jingan District, Shanghai, People's

Republic of China

Tel +86-02I-66307249

Fax +86-02I-6630177I

Email ywei@tongji.edu.cn
Purpose: LAAO has been an alternative therapy to oral anticoagulants (OACs) for stroke prophylaxis in patients with nonvalvular atrial fibrillation (NVAF) with elevated $\mathrm{CHA}_{2} \mathrm{DS}_{2}-$ Vasc score, but the long-term outcomes of LAAO and its impacts on cardiac electrical and mechanical remodeling remain to be learned. We aimed to describe the impact of left atrial appendage occlusion (LAAO) on atrial remodeling and cardiovascular outcomes within 5-year follow-up.

Patients and Methods: A total of 107 patients with nonvalvular atrial fibrillation (NVAF) undergoing LAAO in the Shanghai Tenth People's Hospital between January 2014 and July 2017 were included. All participants were followed for ECG, transthoracic echocardiography (TTE), and clinical outcomes (including cardiovascular death, heart failure, ischemic stroke/systemic embolism, and pericardial effusion) at 6 and 12 months, and thereafter every 12 months after LAAO discharge until 5 years.

Results: After LAAO, the left atrial diameter significantly increased at 6 months ( $48.6 \pm 6.7 \mathrm{vs}$ $46.5 \pm 7.0 \mathrm{~mm})$; heart rate decreased immediately after the procedure $(78.5 \pm 14.7$ vs $85.3 \pm 21.7$ bpm) when compared with the pre-procedure level. The QTc interval prolongated to the highest value of $460.7 \pm 46.8 \mathrm{~ms}$ at 6 months (pre-procedure level of $433.7 \pm 49.0 \mathrm{~ms}$ ). All these changes return to the pre-procedure level within the follow-up. For clinical outcomes, 51 patients suffered the composite of cardiovascular death $(n=4,3.7 \%)$, heart failure $(n=25,23.4 \%)$, ischemic stroke/ systemic embolism $(n=22,20.6 \%)$, and pericardial effusion $(n=26,26.2 \%)$.

Conclusion: LAAO did not change ECG or TTE characteristics and nonprocedure-related pericardial effusion is common during long-term follow-up. Further studies are warranted to investigate the optimal time frame of anticoagulation in patients undergoing LAAO.

Keywords: atrial fibrillation, left atrial appendage occlusion, ECG, echocardiogram

\section{Introduction}

Nonvalvular atrial fibrillation (NVAF) is one of the most common arrhythmias in clinical practice, with an estimated prevalence of 3\% in adults aged 20 years old or over. ${ }^{1}$ Ischemic stroke is a devastating complication among the NVAF population, and oral anticoagulation (OAC) (including warfarin and new oral anticoagulants [NOAC, such as dabigatran, rivaroxaban, etc.]) has been the therapeutic cornerstone for stroke prophylaxis. ${ }^{2}$ Nevertheless, many patients cannot tolerate long-term OAC because of the high risk for bleeding, economic burden, or simply a desire to avoid OAC. As the majority of intracardiac thrombi generally form in the left atrial appendage (LAA) in patients with NVAF, mechanical left atrial appendage occlusion (LAAO) has developed as a reasonable alternative to OAC in selected patients. $^{3,4}$ 
For the past decade, there are several randomized controlled trials (RCTs) being conducted to investigate the efficacy and safety of LAAO when compared with OACs $^{5-7}$ As the first RCT, PROTECT AF (WATCHMAN Left Atrial Appendage System for Embolic Protection in Patients With Atrial Fibrillation) trial demonstrated that LAAO was superior to warfarin for the composite endpoint including stroke, systemic embolism, or cardiovascular mortality during 3.8 years of follow-up. ${ }^{5}$ As a result, the LAAO has been recommended in the current consensus guidelines for AF-related stroke prevention. ${ }^{1,8}$

Although the clinical usefulness of LAAO in patients with NVAF has been widely studied, ${ }^{9}$ the influence of which on left atrial electrical and mechanical remodeling as well as left ventricular systolic or diastolic function is still not well characterized. In our previous analysis, we demonstrated that the implantation of LAAO devices had changed the QRS axis, reduced heart rate (HR), and prolonged the QTc interval at the end of 1-year follow-up, which was confirmed by ECG and transthoracic echocardiography (TTE) examination. ${ }^{10}$ Herein, we aimed to report the 5 years of follow-up data with respect to the alternations in ECG and TTE characteristics as well as the adverse cardiovascular events in patients with NVAF undergoing LAAO.

\section{Patients and Methods Study Design and Population}

From January 2014 to July 2017, 107 patients with persistent or permanent NVAF who received LAAO were enrolled in this case series analysis. Patients enrolled in the current study must meet the following criteria: 1) age $\geq 18$ years old; 2) NVAF persisting over 3 months; 3 ) $\mathrm{CHADS}_{2}$ score $\geq 2$ and $\mathrm{CHA}_{2} \mathrm{DS}_{2}$-VASc score $\geq 3$; 4) patients unsuitable for long-term OAC therapy, including a well-documented history of bleeding, allergic to OACs, and cannot be adherence with OACs; 5) patients understood the research purpose, voluntarily joined this clinical study with informed consent; 6) patient voluntarily completed the follow-ups following LAAO. Exclusion criteria were classified into several different aspects and detailed in Online Table 1. This study had been registered in CliniclTrials.gov (LAAO-SH [Left Atrial Appendage Occlusion in Patients With Non-valvular Atrial Fibrillation From Shanghai] registry, NCT03987945). This study was performed complying with the
Declaration of Helsinki and was approved by the Ethics Committee of Shanghai Tenth People's Hospital. Informed consent was obtained from all participants.

\section{Follow-Up and Endpoints}

All patients were followed at 6, 12, 24, 36, 48, 60 months after discharge. Demographics, cardiovascular risk factors, comorbidities, as well as chronic medication usage had been comprehensively reviewed and archived based on patients' medical records. TTE was used to evaluate cardiac structure remodeling and function. Moreover, pre- and post-procedure TTE and 12-lead ECG results were also compared. Detailed information concerning echocardiography and ECG measurements were presented in Supplementary Methods. As for clinical outcomes, the primary endpoint was the 5-year major adverse cardiovascular events (MACEs). The MACEs were consisted of: 1) cardiovascular death, 2) heart failure and 3) ischemic stroke or systemic embolism. The secondary endpoints were as follows: 1) puncture site complications, 2) all-cause mortality, 3) pericardial effusion (PE), and 4) major bleeding. Detailed definitions of clinical outcomes were shown in Online Table 2. Follow-up data were collected according to outpatient records.

\section{LAAO Procedures}

All Patients registered in this study underwent percutaneous closure of the LAA using WATCHMAN, LAmbre, Leftear, or Lefort device system (as described in Supplementary Methods and Online Figure 1). The choice of the types of LAAO devices was left to the discretion of the operators. All devices consisted of a trans-septal access sheath, a delivery catheter, and an implantable Nitinol device. Each patient would be given unfractionated heparin to achieve an activated clotting time in the range of 200 s to 300 s and be performed transesophageal echocardiography (TEE) to exclude potential LA thrombus and LAA anatomical abnormalities. Following the femoral vein puncture, the atrial septum puncture device was inserted and a transseptal puncture was performed under the fluoroscopy and TEE guidance. The delivery sheath was delivered via the femoral vein puncture site and crossed over the atrial septal to reach the left atrial appendage to establish the channel. Then the LAA occluder was sent and fixed in the left atrial appendage by the delivery cable to close the entrance of the left atrial appendage and simultaneously block blood flow. The positioning of devices was validated by PASS criteria, including a left atrial angiogram after the implant was placed in LAA. All patients had undergone the 
TEE examination to exclude the possibility of pericardial effusion or thrombosis. After the implantation, antithrombotic therapy was administered according to device-specific recommendations. Generally, within the first 24hours after the intervention, $4000 \mathrm{U}$ of enoxaparin was subcutaneously injected; from Day 2 to 3 months after the intervention, aspirin (100mg/d) combined with clopidogrel $(75 \mathrm{mg} / \mathrm{d})$ were used. After that, all patients without any contradictions would receive aspirin $(100 \mathrm{mg} / \mathrm{d})$ or clopidogrel $(75 \mathrm{mg} / \mathrm{d})$ for long-term thrombosis prophylaxis.

\section{Statistical Analysis}

Continuous variables are expressed as the mean $\pm \mathrm{SD}$ and categorical variables as frequency and percentage. Distributions of samples were examined by the ShapiroWilk test. Independent samples with normal distribution were compared using the Student's $t$-test and for skewed samples using a nonparametric test. The cumulative incidence of clinical outcomes was calculated by the Kaplan-Meier method. All tests were two-sided at the 0.05 significance level. All analyses were conducted using SPSS 16.0 (SPSS Inc., Chicago, IL, USA).

\section{Results}

\section{Baseline Characteristics}

Of 126 NVAF patients initially recruited, 12 were excluded due to echocardiogram characteristics. We also excluded 2 patients because of procedure failure and 5 patients who were lost to follow-up (Figure 1). As such, a total of 107 patients were included in the final analysis, of whom 59, 25, 9, and 14 in the LAmbre, Lefort, WATCHMAN, and Leftear groups, respectively. Patients' demographic and clinical characteristics were shown in Table 1. The mean age was $70.7 \pm 9.5$ years, of whom $48.6 \%$ were over 75 years old. Angiotensin-converting enzyme inhibitor/angiotensin receptor blocker (ACEI/ARB) was prescribed for $48.6 \%$, followed by calcium channel blockers (37.4\%). Persistent NVAF was diagnosed in $72.9 \%$ of patients, and $50.4 \%$ had a history of stroke or transient ischemic attack (TIA). Warfarin was given to $41.1 \%$ of patients, while antiplatelet agents were less likely to be used (usage rates of aspirin and clopidogrel were $19.6 \%$ and $15.0 \%$, respectively). The mean $\mathrm{CHADS}_{2}$ and $\mathrm{CHA}_{2} \mathrm{DS}_{2}$-VASc scores were $2.67 \pm 1.45$ and $4.21 \pm 1.97$, respectively. The mean HAS-BLED score was $3.08 \pm 1.53$. All included patients had received the planned antithrombotic therapy.

Differences were observed regarding patients' characteristics across LAA occluder groups. Individuals in the WATCHMAN group $(n=9)$ were younger $(67.2 \pm 14.5$ years), and less likely to present with persistent AF (44.4\%) and TIA (22.2\%) when compared with other groups. The highest rates of persistent atrial fibrillation and TIA were observed in the LAmbre group, while those with a history of CHF $(32 \%)$ and diabetes $(20.3 \%)$ were less than

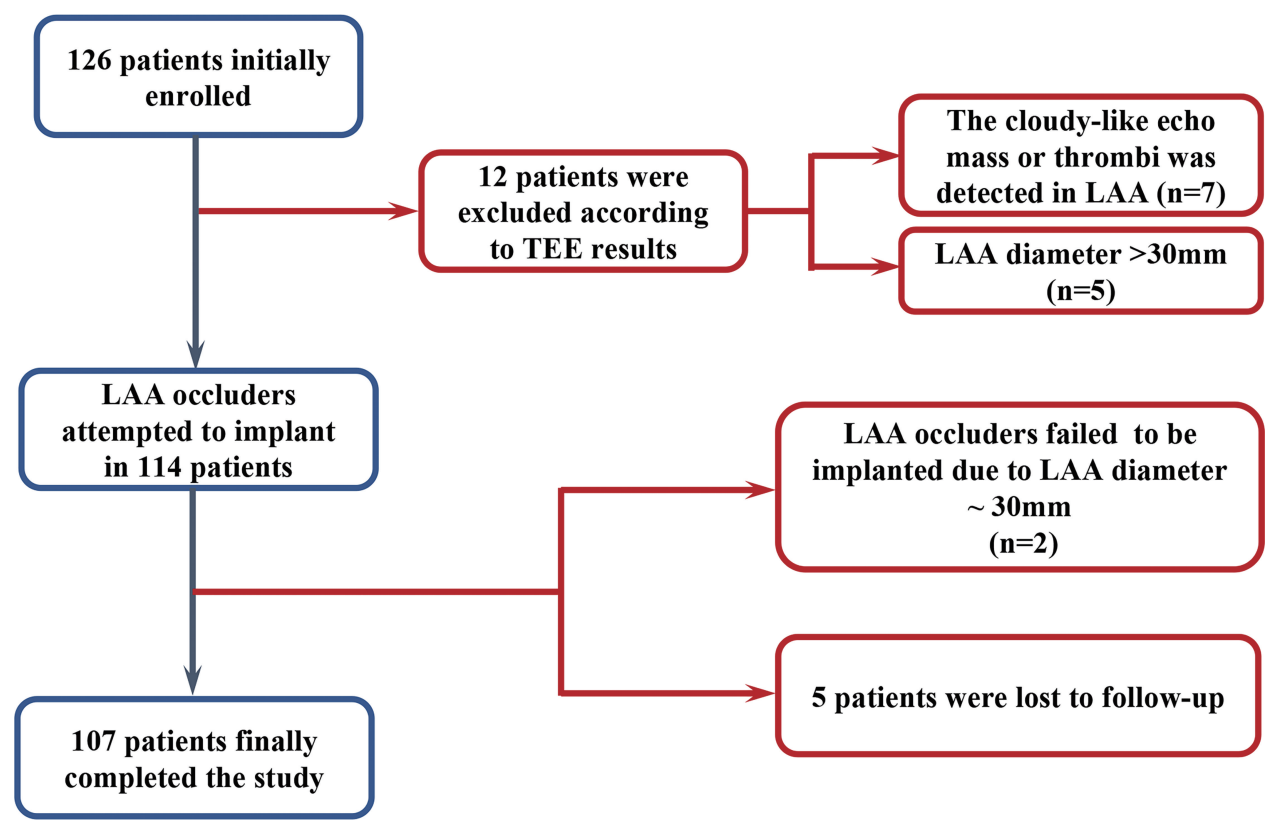

Figure I Flow diagram of the present study. Abbreviations: LAA, left atrial appendage; TEE, transesophageal echocardiography. 
Table I Baseline Characteristics of Patients Stratified by the Types of LAAO Devices

\begin{tabular}{|c|c|c|c|c|c|}
\hline Variables & $\begin{array}{c}\text { Total } \\
(n=107)\end{array}$ & $\begin{array}{l}\text { LAmbre } \\
(n=59)\end{array}$ & $\begin{array}{l}\text { Lefort } \\
(n=25)\end{array}$ & $\begin{array}{l}\text { WATCHMAN } \\
(n=9)\end{array}$ & $\begin{array}{l}\text { Leftear } \\
(n=14)\end{array}$ \\
\hline Age (years) & $70.7 \pm 9.5$ & $71.2 \pm 9.5$ & $71.2 \pm 7.7$ & $67.2 \pm 14.5$ & $70.0 \pm 8.8$ \\
\hline Age $\geq 75$ yrs $(\%, n)$ & $48.6 \%(52)$ & $23.4 \%(25)$ & $13.1 \%(14)$ & $3.7 \%(4)$ & $8.4 \%(9)$ \\
\hline Male/Female & $54 / 53$ & $28 / 31$ & $12 / 13$ & $6 / 3$ & $8 / 6$ \\
\hline Persistent AF $(\%, n)$ & $72.9 \%(78)$ & $11.2 \%(12)$ & $48.6 \%(52)$ & $3.7 \%(4)$ & $9.3 \%(10)$ \\
\hline $\mathrm{SBP}(\mathrm{mmHg})$ & $134.3 \pm 16.7$ & $134.5 \pm 16.0$ & $134.2 \pm 16.4$ & $137.6 \pm 23.4$ & $131.6 \pm 16.6$ \\
\hline $\mathrm{DBP}(\mathrm{mmHg})$ & $77.4 \pm 13.6$ & $79.5 \pm 13.4$ & $74.6 \pm 13.6$ & $76.4 \pm 18.0$ & $74.4 \pm 11.1$ \\
\hline $\mathrm{CHF}(\%, \mathrm{n})$ & $26.2 \%(28)$ & $3.7 \%(4)$ & $7.5 \%(8)$ & $6.5 \%(7)$ & $8.4 \%(9)$ \\
\hline Hypertension $(\%, n)$ & $56.1 \%(60)$ & $35.5 \%(38)$ & $14.0 \%(15)$ & $3.7 \%(4)$ & $2.8 \%(3)$ \\
\hline Diabetes $(\%, n)$ & $30.8 \%(33)$ & $11.2 \%(12)$ & $6.5 \%(7)$ & $5.6 \%(6)$ & $7.5 \%(8)$ \\
\hline Prior Stroke/TIA $(\%, n)$ & $50.4 \%(55)$ & $34.6 \%(37)$ & $9.3 \%(10)$ & $1.9 \%(2)$ & $4.7 \%(5)$ \\
\hline Lipid disorders $(\%, n)$ & $29.0 \%(3 I)$ & $3.7 \%(4)$ & $9.3 \%(10)$ & $6.5 \%(7)$ & $9.3 \%(10)$ \\
\hline Warfarin $(\%, n)$ & $41.1 \%(44)$ & $15.9 \%(17)$ & $8.4 \%(9)$ & $5.6 \%(6)$ & $1 \mathrm{I} .2 \%(12)$ \\
\hline Aspirin $(\%, n)$ & $19.6 \%(21)$ & $9.3 \%(10)$ & $7.5 \%(8)$ & $0.9 \%(1)$ & $1.9 \%(1)$ \\
\hline Clopidogrel $(\%, n)$ & $15.0 \%(16)$ & $5.6 \%(6)$ & $6.5 \%(7)$ & $1.9 \%(2)$ & $0.9 \%(1)$ \\
\hline Statins $(\%, n)$ & $15.9 \%(17)$ & $6.5 \%(7)$ & $3.7 \%(4)$ & 0 & $5.6 \%(6)$ \\
\hline Nitrates $(\%, n)$ & $24.3 \%(26)$ & $5.6 \%(6)$ & $6.5 \%(7)$ & $5.6 \%(6)$ & $6.5 \%(7)$ \\
\hline Amiodarone $(\%, n)$ & $40.2 \%(43)$ & $8.4 \%(9)$ & $12.1 \%(13)$ & $6.5 \%(7)$ & $13.1 \%(14)$ \\
\hline ACEI/ARB $(\%, n)$ & $48.6 \%(52)$ & $26.2 \%(28)$ & $11.2 \%(12)$ & $5.6 \%(6)$ & $5.6 \%(6)$ \\
\hline Beta-blocker $(\%, n)$ & $18.7 \%(20)$ & $7.5 \%(8)$ & $7.5 \%(8)$ & $2.8 \%(3)$ & $0.9 \%(1)$ \\
\hline Diuretics $(\%, \mathrm{n})$ & $29.9 \%(32)$ & $7.5 \%(8)$ & $12.1 \%(13)$ & $4.7 \%(5)$ & $5.6 \%(6)$ \\
\hline CCB $(\%, n)$ & $37.4 \%(40)$ & $15.0 \%(16)$ & $10.3 \%(1 \mathrm{I})$ & $5.6 \%(6)$ & $6.5 \%(7)$ \\
\hline Digoxin $(\%, n)$ & $29.9 \%(32)$ & $4.7 \%(5)$ & $5.6 \%(6)$ & $7.5 \%(8)$ & $12.1 \%(13)$ \\
\hline $\mathrm{CHADS}_{2}$ Score & $2.67 \pm 1.45$ & $2.42 \pm 1.42$ & $2.40 \pm 1.66$ & $3.67 \pm 1.41$ & $3.57 \pm 1.40$ \\
\hline $\mathrm{CHA}_{2} \mathrm{DS}_{2}$-VAS Score & $4.21 \pm 1.97$ & $3.90 \pm 1.77$ & $3.76 \pm 2.28$ & $5.33 \pm 1.58$ & $5.57 \pm 1.42$ \\
\hline HAS-BLED Score & $3.08 \pm 1.53$ & $3.27 \pm 1.68$ & $2.84 \pm 1.43$ & $2.89 \pm 1.27$ & $2.86 \pm 1.23$ \\
\hline NYHA (I/II/III) & $63 / 28 / 15$ & $41 / 10 / 7$ & $17 / 5 / 3$ & $2 / 6 / 1$ & $3 / 7 / 4$ \\
\hline \multicolumn{6}{|l|}{ Post-intervention antithrombotic regimen } \\
\hline Post-intervention to $24 \mathrm{~h}$ : enoxaparin $(\%, \mathrm{n})$ & $100.0 \%(107)$ & $100.0 \%(59)$ & $100.0 \%(25)$ & $100.0 \%(9)$ & $100.0 \%(14)$ \\
\hline $\begin{array}{l}\text { Post-intervention to } 3 \text { months: aspirin combined with } \\
\text { clopidogrel }(\%, n)\end{array}$ & $100.0 \%(107)$ & $100.0 \%(59)$ & $100.0 \%(25)$ & $100.0 \%(9)$ & $100.0 \%(14)$ \\
\hline $\begin{array}{l}\text { Three months after the intervention: aspirin or clopidogrel } \\
(\%, n)\end{array}$ & $100.0 \%(107)$ & $100.0 \%(59)$ & $100.0 \%(25)$ & $100.0 \%(9)$ & $100.0 \%(14)$ \\
\hline
\end{tabular}

Abbreviations: LAAO, left atrial appendage occlusion; SBP, systolic blood pressure; DBP, diastolic blood pressure; $A F$, atrial fibrillation; CHF, congestive heart failure; TIA, transient ischemic attack; ACEl, angiotensin-converting enzyme inhibitor; ARB, angiotensin receptor blocker; CCB, Calcium channel blockers; NYHA; New York Heart Association.

that in other groups. No difference was observed when compared the baseline blood pressure value with that measured post-intervention immediately, and at 6, 12, and 24 months after the LAAO implantation (Online Table 3).

\section{Echocardiographic Characteristics}

The baseline and follow-up echocardiographic data were shown in Table 2. The 6-month follow-up of LAAP (48.6 \pm 6.7 vs $46.5 \pm 7.0 \mathrm{~mm}, \mathrm{p}=0.016$ ) was significantly larger than that of pre-intervention, while the 12 months of followup aotric root diameter was markedly increased $(34.7 \pm 3.5 \mathrm{vs}$ $34.3 \pm 3.6 \mathrm{~mm}, \mathrm{p}=0.022$ ). The other variables including
LVEDD, LVESD, IVSWT, and LVPWT, did not show significant difference at all follow-up time points compared with those before the procedure. All patients' echocardiographic characteristics before LAA occluder implantation and during the follow-up period based on gender and age ( $<75$ years vs $\geq 75$ years) were demonstrated in Online Tables 4-7.

\section{Electrocardiographic Characteristics}

Table 3 demonstrated the baseline and follow-up electrocardiographic data. These findings indicated that the heart rate $(\mathrm{HR})$ decreased $(78.5 \pm 14.7$ vs $85.3 \pm 21.7 \mathrm{bpm}, \mathrm{p}=$ 
Table 2 Echocardiographic Variables According to Follow-Up Visits

\begin{tabular}{|c|c|c|c|c|c|c|c|c|c|}
\hline Variables & $\begin{array}{c}\text { Pre- } \\
\text { Intervention }\end{array}$ & $\begin{array}{l}\text { Follow- } \\
\text { Up at } 6 \\
\text { Months }\end{array}$ & P-value* & $\begin{array}{l}\text { Follow- } \\
\text { Up at I } 2 \\
\text { Months }\end{array}$ & P-value $^{\dagger}$ & $\begin{array}{l}\text { Follow- } \\
\text { Up at } 24 \\
\text { Months }\end{array}$ & P-value ${ }^{\ddagger}$ & $\begin{array}{l}\text { Follow- } \\
\text { Up at } 36 \\
\text { Months }\end{array}$ & P-value ${ }^{\S}$ \\
\hline Aortic root diameter $(\mathrm{mm})$ & $34.3 \pm 3.6$ & $34.8 \pm 3.9$ & 0.711 & $34.7 \pm 3.5$ & 0.022 & $35.5 \pm 3.5$ & 0.118 & $34.5 \pm 4.0$ & 0.167 \\
\hline LA AP diameter $(\mathrm{mm})$ & $46.5 \pm 7.0$ & $48.6 \pm 6.7$ & 0.016 & $47.0 \pm 6.3$ & 0.087 & $46.6 \pm 5.7$ & 0.617 & $46.0 \pm 5.6$ & 0.393 \\
\hline LVEDD (mm) & $47.3 \pm 5.1$ & $48.4 \pm 5.2$ & 0.223 & $47.3 \pm 5.1$ & 0.690 & $48.4 \pm 4.1$ & 0.277 & $46.4 \pm 4.5$ & 0.828 \\
\hline LVESD (mm) & $31.4 \pm 5.4$ & $31.7 \pm 6.7$ & 0.170 & $31.2 \pm 6.0$ & 0.150 & $31.5 \pm 5.2$ & 0.208 & $30.2 \pm 4.5$ & 0.095 \\
\hline IVSWT (mm) & $10.3 \pm 2.1$ & $10.2 \pm 1.4$ & 0.776 & $10.2 \pm 1.9$ & 1.000 & $11.2 \pm 3.0$ & 0.684 & $11.0 \pm 3.0$ & 0.148 \\
\hline LVPWT (mm) & $9.8 \pm 1.3$ & $10.0 \pm 1.1$ & 0.358 & $10.0 \pm 1.2$ & 0.727 & $10.4 \pm 1.0$ & 0.299 & $10.3 \pm 1.9$ & 0.714 \\
\hline LVEF (\%) & $59.8 \pm 8.4$ & $60.4 \pm 8.2$ & 0.382 & $59.8 \pm 7.2$ & 0.930 & $58.0 \pm 6.1$ & 0.678 & $60.1 \pm 7.6$ & 0.123 \\
\hline
\end{tabular}

Notes: Values are presented as mean \pm SD. *P-value represents a comparison between follow-up at 6 months versus pre-intervention for echocardiographic variables after LAAO operation. ${ }^{\dagger} \mathrm{P}$-value represents a comparison between follow-up at 12 months versus pre-intervention for echocardiographic variables after $L A A O$ operation. ${ }^{\ddagger} \mathrm{P}$-value represents a comparison between follow-up at 24 months versus pre-intervention for echocardiographic variables after LAAO operation. ${ }^{\S} \mathrm{P}$-value represents a comparison between follow-up at 36 months versus pre-intervention for echocardiographic variables after LAAO operation.

Abbreviations: LVEDD, left ventricular end-diastolic dimension; LVESD, left ventricular end-systolic dimension; IVSWT, interventricular septal wall thickness; LVPWT, left ventricular posterior wall thickness; LVEF, left ventricular ejection fraction; LA, left atrium; AP, anteroposterior.

Table 3 The Comparison Between Each Follow-Up Time Point and Pre-Intervention ECG Data

\begin{tabular}{|c|c|c|c|c|c|c|c|c|c|}
\hline Variables & $\begin{array}{c}\text { Pre- } \\
\text { Intervention }\end{array}$ & $\begin{array}{c}\text { Post- } \\
\text { Intervention }\end{array}$ & P-value* & $\begin{array}{l}\text { Follow- } \\
\text { Up at } 6 \\
\text { Months }\end{array}$ & P-value $^{\dagger}$ & $\begin{array}{l}\text { Follow- } \\
\text { Up at I } 2 \\
\text { Months }\end{array}$ & P-value ${ }^{\ddagger}$ & $\begin{array}{l}\text { Follow- } \\
\text { Up at } 24 \\
\text { Months }\end{array}$ & P-value ${ }^{\S}$ \\
\hline Heart rate (bpm) & $85.3 \pm 21.7$ & $78.5 \pm 14.7$ & 0.007 & $82.1 \pm 16.2$ & 0.830 & $84.8 \pm 16.5$ & 0.675 & $85.5 \pm 20.9$ & 0.052 \\
\hline QRS interval (ms) & $104.6 \pm 28.2$ & $99.6 \pm 26.0$ & 0.561 & $101.0 \pm 33.7$ & 0.132 & $100.1 \pm 25.5$ & 0.370 & $100.9 \pm 27.9$ & 0.713 \\
\hline QT interval (ms) & $386.3 \pm 51.7$ & $398.5 \pm 50.7$ & 0.016 & $400.0 \pm 56.7$ & 0.883 & $376.4 \pm 71.1$ & 0.143 & $358.4 \pm 49.8$ & 0.188 \\
\hline $\mathrm{QTc}(\mathrm{ms})$ & $433.7 \pm 49.0$ & $443.1 \pm 46.3$ & 0.182 & $460.7 \pm 46.8$ & 0.036 & $452.8 \pm 45.7$ & 0.381 & $420.3 \pm 47.1$ & 0.178 \\
\hline QRS axis (degrees) & $20.6 \pm 39.7$ & $26.6 \pm 39.5$ & 0.084 & $29.3 \pm 45.2$ & $0.28 I$ & $23.8 \pm 43.8$ & 0.851 & $37.2 \pm 30.5$ & 0.443 \\
\hline
\end{tabular}

Notes: *P-value represents the comparison between post-intervention versus pre-intervention for ECG variables after LAAO intervention. ${ }^{\dagger} \mathrm{P}$-value represents the comparison between follow-up at 6 months versus pre-intervention for ECG variables after LAAO intervention. ${ }^{\ddagger} \mathrm{P}$-value represents the comparison between follow-up at 12 months versus pre-intervention for ECG variables after LAAO intervention. ${ }^{\S} \mathrm{P}$-value represents the comparison between follow-up at 24 months versus pre-intervention for ECG variables after LAAO intervention.

$0.007)$ and QT interval lengthened (398.5 \pm 50.7 vs 386.3 $\pm 51.7 \mathrm{~ms}, \mathrm{p}=0.016$ ) at post-intervention, and seemingly recovered to the pre-intervention level in the other followup periods. In addition, QTc was significantly prolonged within the 6-month follow-up $(460.7 \pm 46.8$ vs $433.7 \pm$ $49.0 \mathrm{p}=0.036$ ), and other ECG variables such as QRS interval and QRS axis did not change significantly. Online Tables 8-10 outlined the difference between preintervention and post-intervention or 24-month follow-up ECG data according to gender and age ( $<75$ years vs $\geq 75$ years).

\section{Clinical Outcomes}

Clinical outcomes are presented in Table 4. In the study population, fifty-one patients developed MACEs during up to 5 years follow-up, of whom $4(3.7 \%)$ patients were with cardiovascular death, 25 (23.4\%) were with heart failure, 11 $(10.3 \%)$ were with stroke, and $11(10.3 \%)$ were with systemic embolism. As to the secondary endpoint events, puncture site complications were found in 7 patients $(6.5 \%)$ and all-cause mortality in 8 patients $(7.5 \%)$. PE was found in 14 patients $(13.1 \%)$ in the first year, and the number of cases gradually decreased in the following years, 8 cases $(7.5 \%)$ in the second year, 6 cases $(5.6 \%)$ in the third year. Also, we observed bleeding events occurred in 7 cases $(6.5 \%)$ during the follow-up period.

Figure 2 illustrated the Kaplan-Meier curve of MACE according to different occluder types, gender, and age. No statistical significance was observed among patients stratified by the types of LAAO devices or gender, but the younger individuals tended to benefit more from the LAAO when compared with the elderly $(p=0.048)$.

\section{Discussion}

In this prospective case analysis of 107 patients with NVAF who had undergone the LAAO procedure, we found 1) the ischemic stroke and $\mathrm{PE}$ were not an infrequent event during the long-term follow-up; 2) no differences were observed 
Table 4 The Clinical Outcomes in Patients with LAAO Within 5-Years Follow-Up

\begin{tabular}{|c|c|c|}
\hline \multicolumn{2}{|l|}{ Events } & Total $(n=107)$ \\
\hline \multicolumn{2}{|c|}{ Mean follow-up time (months) } & $42.7 \pm 16.8$ \\
\hline \multicolumn{3}{|l|}{ I. MACEs } \\
\hline \multicolumn{2}{|c|}{ Cardiovascular mortality } & $3.7 \%(4)$ \\
\hline \multicolumn{2}{|l|}{ Heart Failure } & $23.4 \%(25)$ \\
\hline \multicolumn{2}{|c|}{ Stroke/systemic embolism } & $10.3 \%(11)$ \\
\hline \multicolumn{2}{|l|}{ Systemic embolism } & $10.3 \%(11)$ \\
\hline \multicolumn{3}{|c|}{ 2. Secondary endpoints } \\
\hline \multirow{2}{*}{\multicolumn{2}{|c|}{$\begin{array}{l}\text { Puncture site complications } \\
\text { All-cause mortality }\end{array}$}} & $6.5 \%(7)$ \\
\hline & & $7.5 \%(8)$ \\
\hline \multirow[t]{3}{*}{ Pericardial effusion } & I-year & $13.1 \%(14)$ \\
\hline & 2-year & $7.5 \%(8)$ \\
\hline & 3-year & $5.6 \%(6)$ \\
\hline \multicolumn{2}{|l|}{ Bleeding } & $6.5 \%(7)$ \\
\hline
\end{tabular}

Abbreviations: LAAO, left atrial appendage occlusion; MACE, major adverse cardiovascular events.

among the different LAA occluders regarding adverse cardiovascular events at 5 years; and 3) the use of LAAO only transiently (within 6 months) affected the characteristics of ECG and TTE, which eventually returned to the baseline level. To our best knowledge, this is the first study that reported the long-term changes of ECG as well as TTE in the NVAF population with LAAO treatment.

In our previous study, we had reported the occurrence of LA enlargement after LAAO during 1-year follow-up, which was similar to that in the present analysis. Thereafter, the LA diameter appeared to decrease and eventually return to the pre-intervention status at 2 years after LAAO. ${ }^{11}$ The precise mechanisms for these geometric changes in the left atrium were still unknown, and we assumed that the alterations in LA filling pressure and systemic homeostasis, ${ }^{11}$ as well as neuroendocrine regulation after LAAO, may be attributable. ${ }^{12}$ LA enlargement has been demonstrated as an important risk factor indicating a detrimental prognosis for individuals with NVAF. In a prospective cohort study with NVAF, participants who suffered an acute ischemic stroke event were found to have an increased indexed-left atrial diameter which was independently associated with a 1.6-fold elevated risk of stroke recurrence (hazard ratio: $1.60,95 \% \mathrm{CI}$ : 1.30-1.98) after multivariable adjustment. ${ }^{13}$ The clinical usefulness of left atrial volume (LAV) to evaluate the risk of recurrent AF after catheter ablation had been explored in a meta-analysis, where the increased LAV or LAV index was significantly associated with $\mathrm{AF}$ recurrence after ablation. ${ }^{14}$ Nevertheless, data regarding the prognostic implication of LA size in patients undergoing LAAO are still lacking and deserve further investigation.

Both heart rate and QTc interval have been recognized as pivotal factors for the risk evaluation of adverse outcomes among patients with NVAF. ${ }^{15-18}$ In a combined analysis of AFFIRM (Atrial Fibrillation Follow-up Investigation of Rhythm Management) and AF-CHF (Rhythm Control versus Rate Control for Atrial Fibrillation and Heart Failure) trials, a higher baseline heart rate (>114 bpm) was independently associated with increased risks of all-cause and cardiovascular hospitalizations compared with those with a lower heart rate. ${ }^{19}$ It has also been reported that each 1-SD increase in QTc interval was pronouncedly associated with increased risk of heart failure hospitalization (HR:1.3, 95\% CI: 1.1-1.6), a composite of cardiovascular death, myocardial infarction, stroke, systemic arterial embolism (HR:1.2, 95\% CI: 1.0-1.4), and all-cause mortality (HR:1.3, 95\% CI: 1.0-1.6). ${ }^{20}$ Our 2-year ECG data demonstrated dynamic changes with heart rate being decreased significantly after LAAO but recovered to the baseline level within 6 months. A similar pattern was also observed for the QTc, as the QTc interval gradually prolongated and reached the
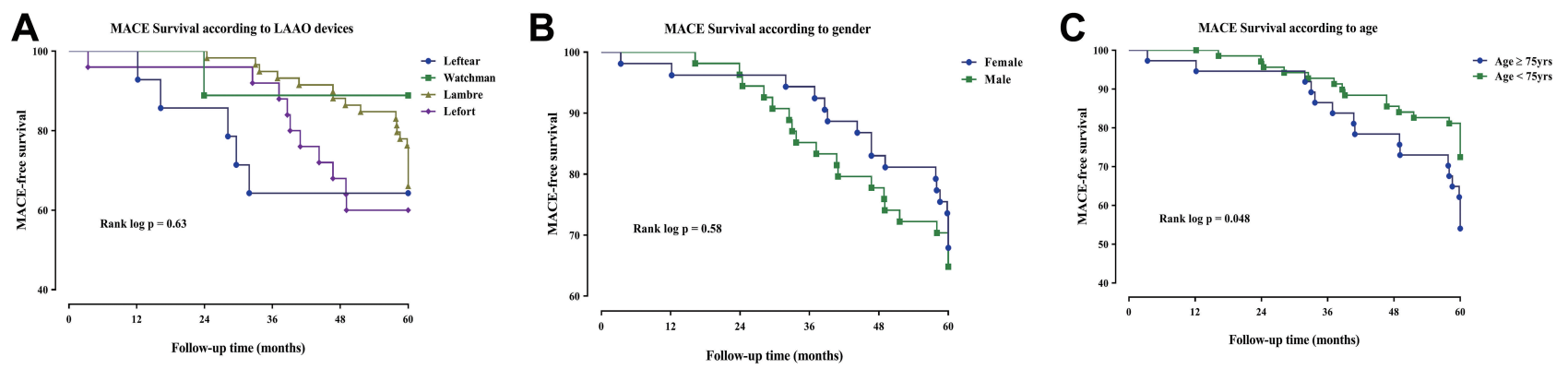

Figure 2 Survival analysis regarding MACE at 5 years of follow-up according to (A) Types of LAAO devices, (B) gender, and (C) age. 
highest value of $460.7 \pm 46.8 \mathrm{~ms}$ at 6 months. The reasons for these "transient" ECG changes were unclear although neurohumoral alterations after LAAO can happen. Other contributing factors might include the use of Vaughan Williams type III antiarrhythmic drugs as well as ratecontrol agents although there were no significant changes in these medications following LAAO in our patient population. Taken together, further studies are warranted to address the effect of these ECG changes on outcomes of NVAF patients receiving LAAO.

During up to 5 years of follow-up, PE (26.2\%) was confirmed by TTE, making it one of the most common findings after the implementation of LAA devices. This was followed by heart failure requiring hospitalization (23.5\%). As all procedure-related PE events had been excluded by the TTE examination before discharge, those episodes that occurred during long-term follow-up were unlikely to be caused by inadequate implantation. ${ }^{21,22}$ Similarly, using data from the Food and Drug Administration Manufacturer and User Facility Device Experience (MAUDE) database, Jazayeri et al reported the $\mathrm{PE}$ as the most common complications after LAAO implantation no matter using the WATCHMAN or LARIAT device. ${ }^{23}$ Despite the uncertainty of underlying mechanisms for the presence of these PE, atrial remodeling, chronic pericarditis, ${ }^{24}$ concomitant heart failure, ${ }^{25}$ etc. might be attributed.

In the $2019 \mathrm{AHA} / \mathrm{ACC} / \mathrm{HRS}$ guideline, LAAO is recommended as an $\mathrm{IIb}$ class for stroke prevention in patients with $\mathrm{AF}^{8}$ but the time frame of post-procedure antithrombotic therapy is not well described. In this study, despite the use of antiplatelet or anticoagulation agents according to occluder types, the 5-year cumulative incidence of ischemic stroke $(10.3 \%)$ was higher than that in the PROTECT-AF (5.2\%) and PREVAIL (6.3\%) trials. ${ }^{26}$ Of note, the $\mathrm{CHA}_{2} \mathrm{DS}_{2}$-VASc score in this analyzed population $(4.2 \pm 2.0)$ was higher than that in the abovementioned 2 trials $(3.4 \pm 1.5$ and $4.0 \pm 1.2$ for PROTECT-AF and PREVAIL trials, respectively), which might contribute to the higher incidence of ischemic stroke. Additionally, the higher incidence rate of ischemic stroke might also be related to the lower post-LAAO anticoagulation usage in the present analysis (only used for WATCHMAN and Lefort devices [34/107, $31.8 \%]$ ). Therefore, our results underscore the necessity of anticoagulation therapy in the NVAF population undergoing LAAO and indicate that further studies investigating the tailored antithrombotic/anticoagulation time frame based on individuals' stroke risk would be highly desirable.

Although several kinds of LAA occluders had been utilized in clinical trials to compare the efficacy and safety of LAAO and oral anticoagulation therapy in stroke prophylaxis, ${ }^{24,26,27}$ scarce data had been available to make a head-to-head comparison between these devices. $^{23}$ In our study, we demonstrated that no significant difference existed in the occurrence of MACE $(p=$ 0.63 ) across four LAA devices. Given the observational nature and relatively small sample size of the present analysis, randomized controlled trials are necessary to compare the clinical usefulness of different devices.

\section{Conclusion}

This was the first study describing the long-term impact of LAAO on patients' ECG and TTE characteristics as well as clinical outcomes. Despite the short-term alternations in the ECG and TTE parameters, no significant difference was observed at long-term follow-up. Neither PE nor ischemic stroke is a rare event after LAAO during the 5-year follow-up. Therefore, our study indicates that a comprehensive understanding of patients' baseline stroke risk, ECG, and TTE characteristics may help in individualized clinical decision-making for stroke prevention with LAAO.

\section{Data Sharing Statement}

The analytical methods and study materials will be made available upon reasonable request. Researchers can contact the corresponding author for more information.

\section{Acknowledgments}

This work was supported by the National Natural Science Foundation of China (grant 30800466, grant 81270193) and the Natural Science Foundation of Shanghai (grant 18ZR1429700) to Yidong Wei; the Shanghai Sailing Program (grant 19YF1437900) and the National Natural Science Foundation of China (grant 81900385) to Baoxin Liu.

\section{Author Contributions}

All authors made a significant contribution to the work reported, whether that is in the conception, study design, execution, acquisition of data, analysis, and interpretation, or in all these areas; took part in drafting, revising, or critically reviewing the article; gave final approval of the version to be published; have agreed on the journal to 
which the article has been submitted; and agree to be accountable for all aspects of the work.

\section{Disclosure}

The authors report no conflicts of interest in this work.

\section{References}

1. Kirchhof P, Benussi S, Kotecha D, et al. 2016 ESC Guidelines for the management of atrial fibrillation developed in collaboration with EACTS. Eur Heart J. 2016;37(38):2893-2962.

2. RuffCT, Giugliano RP, Braunwald E, et al. Comparison of the efficacy and safety of new oral anticoagulants with warfarin in patients with atrial fibrillation: a meta-analysis of randomised trials. Lancet. 2014;383 (9921):955-962. doi:10.1016/S0140-6736(13)62343-0

3. Stoddard MF, Dawkins PR, Prince CR, Ammash NM. Left atrial appendage thrombus is not uncommon in patients with acute atrial fibrillation and a recent embolic event: a transesophageal echocardiographic study. J Am Coll Cardiol. 1995;25(2):452-459. doi:10.1016/ 0735-1097(94)00396-8

4. Turagam M, Velagapudi $\mathrm{P}, \mathrm{Kar} \mathrm{S}$, et al. Cardiovascular Therapies Targeting Left Atrial Appendage. J Am Coll Cardiol. 2018;72 (4):448-463. doi:10.1016/j.jacc.2018.05.048

5. Holmes DR, Reddy VY, Turi ZG, et al. Percutaneous closure of the left atrial appendage versus warfarin therapy for prevention of stroke in patients with atrial fibrillation: a randomised non-inferiority trial. Lancet. 2009;374(9689):534-542. doi:10.1016/S0140-6736(09)61343-X

6. Holmes DR Jr, Kar S, Price MJ, et al. Prospective randomized evaluation of the Watchman Left Atrial Appendage Closure device in patients with atrial fibrillation versus long-term warfarin therapy: the PREVAIL trial. $J \mathrm{Am}$ Coll Cardiol. 2014;64(1):1-12. doi:10.1016/j.jacc.2014.04.029

7. Osmancik P, Herman D, Neuzil P, et al. Left atrial appendage closure versus direct oral anticoagulants in high-risk patients with atrial fibrillation. $J$ Am Coll Cardiol. 2020;75(25):3122-3135. doi:10.1016/j.jacc.2020.04.067

8. January CT, Wann LS, Calkins H, et al. 2019 AHA/ACC/HRS focused update of the 2014 AHA/ACC/HRS Guideline for the Management of Patients With Atrial Fibrillation: a Report of the American College of Cardiology/American Heart Association Task Force on Clinical Practice Guidelines and the Heart Rhythm Society in Collaboration With the Society of Thoracic Surgeons. Circulation. 2019;140(2):e125-e151. doi:10.1161/CIR.0000000000000665

9. Turagam M, Osmancik P, Neuzil P, Dukkipati S, Reddy V. Left atrial appendage closure versus oral anticoagulants in atrial fibrillation: a meta-analysis of randomized trials. J Am Coll Cardiol. 2020;76 (23):2795-2797. doi:10.1016/j.jacc.2020.08.089

10. Jie Q, Wang D, Liu B, et al. Does left atrial appendage (LAA) occlusion device alter the echocardiography and electrocardiogram parameters in patients with atrial fibrillation? Int $J$ Cardiol. 2016;215:494-501. doi:10.1016/j.ijcard.2016.03.204

11. Turagam M, Vuddanda V, Verberkmoes N, et al. Epicardial left atrial appendage exclusion reduces blood pressure in patients with atrial fibrillation and hypertension. $J$ Am Coll Cardiol. 2018;72 (12):1346-1353. doi:10.1016/j.jacc.2018.06.066

12. Lakkireddy D, Turagam M, Afzal M, et al. Left atrial appendage closure and systemic homeostasis: the LAA HOMEOSTASIS Study. J Am Coll Cardiol. 2018;71(2):135-144. doi:10.1016/j.jacc.2017.10.092
13. Ogata T, Matsuo R, Kiyuna F, et al. Left atrial size and long-term risk of recurrent stroke after acute ischemic stroke in patients with nonvalvular atrial fibrillation. $J$ Am Heart Assoc. 2017;6(8):e006402. doi:10.1161/JAHA.117.006402

14. Njoku A, Kannabhiran M, Arora R, et al. Left atrial volume predicts atrial fibrillation recurrence after radiofrequency ablation: a meta-analysis. Europace. 2018;20(1):33-42. doi:10.1093/europace/ eux013

15. Li S-J, Sartipy U, Lund LH, et al. Prognostic significance of resting heart rate and use of $\beta$-blockers in atrial fibrillation and sinus rhythm in patients with heart failure and reduced ejection fraction: findings from the swedish heart failure registry. Circ Heart Fail. 2015;8 (5):871-879. doi:10.1161/CIRCHEARTFAILURE.115.002285

16. Riad FS, Razak E, Saba S, Shalaby A, Nemec J. Recent heart rate history affects QT interval duration in atrial fibrillation. PLoS One. 2017;12(3):e0172962-e0172962. doi:10.1371/journal.pone.0172962

17. Huang HD, Waks JW, Steinhaus DA, Zimetbaum P. Magnitude of increase in QTc interval after initiation of dofetilide in patients with persistent atrial fibrillation is associated with increased rates of pharmacological cardioversion and long-term freedom from recurrent atrial fibrillation. Heart Rhythm. 2016;13(7):1410-1417. doi:10.10 16/j.hrthm.2016.02.016

18. Wen S-N, Liu N, Li S-N, et al. QTc interval prolongation predicts arrhythmia recurrence after catheter ablation of atrial fibrillation in patients with hypertrophic cardiomyopathy. Circ J. 2015;79 (5):1024-1030. doi:10.1253/circj.CJ-14-1290

19. Andrade JG, Roy D, Wyse DG, et al. Heart rate and adverse outcomes in patients with atrial fibrillation: a combined AFFIRM and AF-CHF substudy. Heart Rhythm. 2016;13(1):54-61. doi:10.1016/j. hrthm.2015.08.028

20. Reusser A, Blum S, Aeschbacher S, et al. QTc interval, cardiovascular events and mortality in patients with atrial fibrillation. Int J Cardiol. 2018;252:101-105. doi:10.1016/j.ijcard.2017.11.078

21. Schmidt B, Betts TR, Sievert H, et al. Incidence of pericardial effusion after left atrial appendage closure: the impact of underlying heart rhythm-Data from the EWOLUTION study. $J$ Cardiovasc Electrophysiol. 2018;29(7):973-978. doi:10.1111/jce.13626

22. Reddy VY, Holmes D, Doshi SK, Neuzil P, Kar S. Safety of percutaneous left atrial appendage closure: results from the watchman left atrial appendage system for embolic protection in patients with $\mathrm{AF}$ (PROTECT AF) clinical trial and the continued access registry. Circulation. 2011;123(4):417-424. doi:10.1161/CIRCULATIONAHA. 110.976449

23. Jazayeri M, Vuddanda V, Turagam M, et al. Safety profiles of percutaneous left atrial appendage closure devices: an analysis of the food and drug administration manufacturer and user facility device experience (MAUDE) database from 2009 to 2016. J Cardiovasc Electrophysiol. 2018;29(1):5-13. doi:10.1111/jce.13362

24. Saw J, Lempereur M. Percutaneous left atrial appendage closure: procedural techniques and outcomes. JACC Cardiovasc Interv. 2014;7(11):1205-1220. doi:10.1016/j.jcin.2014.05.026

25. Kataoka H. Pericardial and pleural effusions in decompensated chronic heart failure. Am Heart J. 2000;139(5):918-923. doi:10. 1016/S0002-8703(00)90026-7

26. Reddy VY, Doshi SK, Kar S, et al. 5-year outcomes after left atrial appendage closure: from the PREVAIL and PROTECT AF Trials. J Am Coll Cardiol. 2017;70(24):2964-2975. doi:10.1016/j.jacc.2017. 10.021

27. Giudici MC, Bhave PD. Left atrial appendage closure device in atrial fibrillation. Cardiol Clin. 2017;35(2):297-300. doi:10.1016/j.ccl.20 16.12 .011 


\section{Publish your work in this journal}

Clinical Interventions in Aging is an international, peer-reviewed journal focusing on evidence-based reports on the value or lack thereof of treatments intended to prevent or delay the onset of maladaptive correlates of aging in human beings. This journal is indexed on PubMed Central, MedLine, CAS, Scopus and the Elsevier
Bibliographic databases. The manuscript management system is completely online and includes a very quick and fair peer-review system, which is all easy to use. Visit http://www.dovepress.com/ testimonials.php to read real quotes from published authors.

Submit your manuscript here: https://www.dovepress.com/clinical-interventions-in-aging-journal 